\title{
¿Cuántas comidas debo comer cada día?'
}

\section{Zainab Alyousif y Wendy Dahl; traducción por Daniela Rivero Mendoza. ${ }^{2}$}

Para los adultos mayores que desean mantenerse saludables, una pregunta común es: ¿Cuántas comidas debo comer al día? ¿Tres o dos comidas al día? Además, ¿debo comer meriendas entre mis comidas?

Antes de decidir cuántas comidas debe comer, definamos los términos "comida" y "merienda".

Una comida es una ocasión para comer, como el desayuno, el almuerzo o la cena. La comida puede ocurrir en cualquier lugar, en casa o fuera. Una comida se considera más grande que una merienda.

Una merienda es un alimento o bebida que se come entre comidas y generalmente es más pequeño que una comida. A menudo, los bocadillos requieren poca o ninguna preparación, como una pieza de fruta, un tazón de cereal, o queso y galletas.

Para los adultos mayores sanos, la cantidad de comidas no importa tanto como la cantidad total de alimentos consumidos en un día. Lo más importante es la calidad nutricional de sus comidas y meriendas y las calorías totales consumidas. Merendar está bien, siempre y cuando se hagan elecciones saludables. Sin embargo, es posible que aquellos individuos con algún problema de salud, como diabetes, deban seguir una dieta o un patrón de meriendas recetado por un médico y dietista.

MiPlato del Departamento de Agricultura de los Estados Unidos (USDA) es una guía de planificación de comidas simple para ayudarlo a planificar comidas saludables utilizando alimentos de los cinco grupos de alimentos: frutas, verduras, proteínas, granos y productos lácteos.

Actualmente, la dieta estadounidense es baja en frutas, verduras y productos lácteos y alta en calorías, azúcares agregados, grasas saturadas y sodio. La mayoría de los estadounidenses cumplen o exceden su ingesta recomendada de granos totales, pero no llegan a la cantidad recomendada de granos integrales. Se recomienda incluir al menos tres de los cinco grupos de alimentos en cada comida (consulte la Figura 1). Una merienda debe incluir alimentos de uno o más de los grupos de alimentos recomendados.

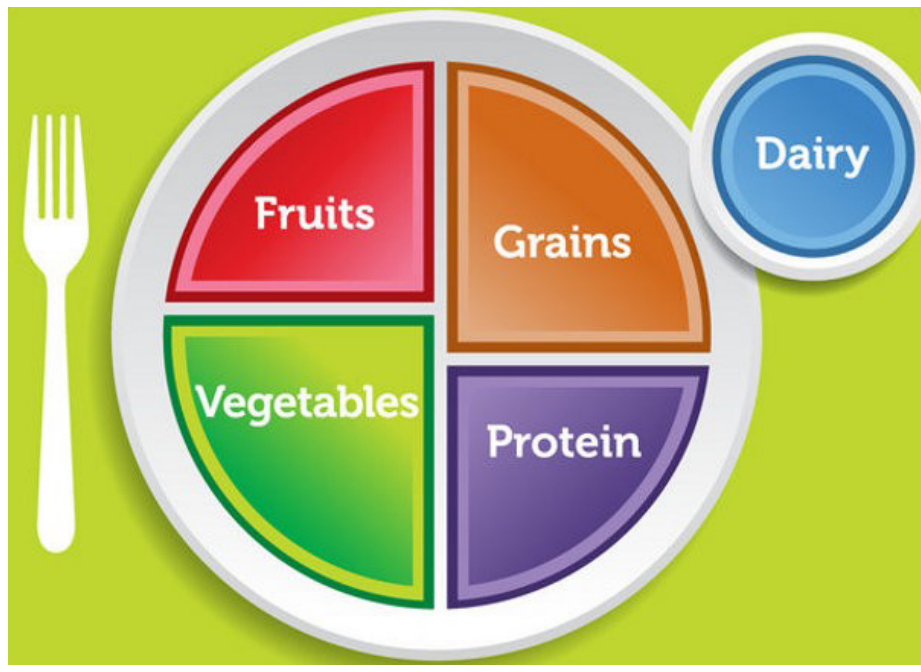

Figura 1. MiPlato.

Credits: https://www.choosemyplate.gov/

1. Este documento, FSHN18-10-Span, es uno de una serie de publicaciones del Food Science and Human Nutrition, Servicio de Extensión Cooperativa de la Florida, Instituto de Alimentos y Ciencias Agrícolas, Universidad de la Florida (UF/IFAS Extension). Fecha de primera publicación: November 2019. Visite nuestro sitio web EDIS en <https://edis.ifas.ufl.edu>. This is the Spanish version of FSHN18-10, How Many Meals Should I Eat Each Day? (https:// edis.ifas.ufl.edu/fs313).

2. Zainab Alyousif, estudiante, y Wendy J. Dahl, profesora asociada; Departamento de Ciencia de los Alimentos y Nutrición Humana; UF/IFAS Extension, Gainesville, FL 32611. Traducción por Daniela Rivero Mendoza.

The Institute of Food and Agricultural Sciences (IFAS) is an Equal Opportunity Institution authorized to provide research, educational information and other services

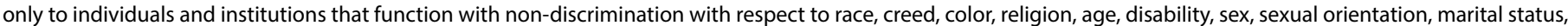

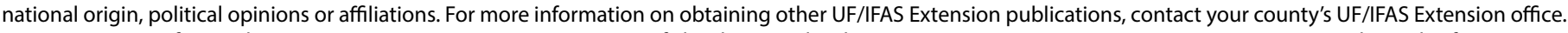
U.S. Department of Agriculture, UF/IFAS Extension Service, University of Florida, IFAS, Florida A \& M University Cooperative Extension Program, and Boards of County Commissioners Cooperating. Nick T. Place, dean for UF/IFAS Extension. 
Comer bien y tomar decisiones saludables es importante, no importa cuál sea su edad. Sin embargo, a medida que envejece, su cuerpo cambia y comer una variedad de alimentos se vuelve aún más importante. Elegir alimentos de todos los grupos de alimentos le ayudará a obtener los nutrientes que necesita para promover una buena salud y prevenir enfermedades.

Las guías dietéticas para los estadounidenses sugieren que las personas de 50 años de edad y mayores elijan los siguientes alimentos y cantidades todos los días (USDHHS y USDA 2015). Las recomendaciones diarias individuales varían según la edad, la actividad y el tamaño corporal. Además, los hombres suelen necesitar más calorías y, por lo tanto, más alimentos que las mujeres. Las ingestas de energía recomendadas van desde aproximadamente 1600 calorías por día para una mujer mayor y sedentaria hasta 2600 calorías para un hombre mayor y activo. A continuación se presentan algunas guías generales para la ingesta de grupos de alimentos.

- Frutas: $1 \frac{1 / 2}{2}$ a $2^{1 / 2}$ tazas

- Verduras: 2 a $3 \frac{1}{2}$ tazas

- Granos: 5 a 10 onzas

- Proteína: 5 a 7 onzas

- Productos lácteos: 3 tazas de leche descremada o baja en grasa

- Aceites: 5 a 8 cucharaditas.

- Limite las grasas sólidas, los azúcares agregados y el sodio (sal)

Las frutas y verduras son importantes para los adultos mayores, ya que proporcionan vitaminas, minerales, fibra y energía. Los granos, en particular los granos integrales, proporcionan vitaminas, minerales y fibra, así como carbohidratos para obtener energía y contienen también un poco de proteína. Los alimentos ricos en proteínas, como carne, pollo, pescado y legumbres, son especialmente importantes a medida que envejecemos para mantener el músculo y la energía. Los productos lácteos, como la leche de vaca, proporcionan proteína, así como vitamina $\mathrm{D}$ y calcio, nutrientes que pueden ser bajos en las dietas de los adultos mayores.

\section{Resumen}

Comer de manera saludable no se trata tanto de la cantidad de comidas y meriendas consumidas, sino de los tipos y las cantidades de alimentos totales consumidos en un día. Tratar de cumplir con las porciones recomendadas de los cinco grupos de alimentos, es decir, frutas, verduras, granos, proteínas y productos lácteos ayudará a promover la buena salud y prevenir enfermedades.

\section{Referencias}

USDHHS and USDA. 2015. "2015-2020 Dietary

Guidelines for Americans. 8th Edition." http://health.gov/

dietaryguidelines/2015/guidelines/ 